Discussion Paper No. 09-070

\title{
A Socio-economic Analysis of Youth Disconnectedness
}

Friedhelm Pfeiffer and Ruben R. Seiberlich

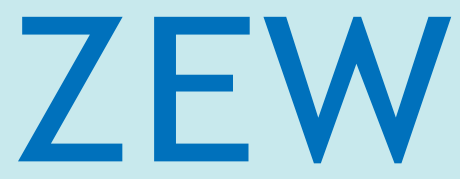

Zentrum für Europäische Wirtschaftsforschung $\mathrm{GmbH}$

Centre for European

Economic Research 
Discussion Paper No. 09-070

\title{
A Socio-economic Analysis of Youth Disconnectedness
}

\author{
Friedhelm Pfeiffer and Ruben R. Seiberlich
}

Download this ZEW Discussion Paper from our ftp server:

ftp://ftp.zew.de/pub/zew-docs/dp/dp09070.pdf

Die Discussion Papers dienen einer möglichst schnellen Verbreitung von neueren Forschungsarbeiten des ZEW. Die Beiträge liegen in alleiniger Verantwortung der Autoren und stellen nicht notwendigerweise die Meinung des ZEW dar.

Discussion Papers are intended to make results of ZEW research promptly available to other economists in order to encourage discussion and suggestions for revisions. The authors are solely responsible for the contents which do not necessarily represent the opinion of the ZEW. 


\section{Non-technical Summary}

In this paper we investigate the prevalence of "disconnectedness" among German youth. Youth disconnectedness can have several dimensions. Unemployment, failure in school, the lack of an intimate relationship and developmental disorders are among the most important ones. Many youths in modern society lack networks to provide emotional support, financial assistance and housing.

Two problems for disconnected youths may arise. First, when loans are difficult to obtain due to imperfections in credit markets, insufficient investment in education and human capital can result if family and friends are not available to provide support. Second, integration into society is contingent upon the passage of a number of tests with formal and informal rules. Those who do not pass such tests or who do not adhere to social rules have a higher probability of future failure. This can create a vicious downward spiral.

The definition of disconnectedness used in our paper is based on economic and social factors. A disconnected individual is one who is not working, not enrolled in school, and not living together with a partner. While there is often a correlation between disconnectedness and anxiety or mood disorders, an investigation with the psychological dimension of disconnectedness is left for future research.

Around $12 \%$ of young people between the ages of 17 and 19 are disconnected according to our definition. This figure has been on the rise since 2002. There is evidence that an adverse family environment is the most decisive variable for being disconnected at 17-to-19 years of age. While there is no evidence that an immigrant background per se contributes to disconnectedness, adolescents with an immigrant background are overrepresented among the disconnected. Disconnectedness seems to stem from having parents with a low educational level and/or from growing up in a broken home. Parents in such families have difficulty providing emotional and material support for their offspring in times of developmental change as well as in times of economic hardship.

We find evidence that economic downturns contribute to disconnectedness with a delayed effect. Following a recession, the most disadvantaged youths seem to suffer most, presumably because recessions aggravate the wounds left from early life adversity. Our results suggest that the current economic crisis will result in an increase in youth disconnectedness in the coming years. In sum, disconnectedness seems to result from low-quality adult mentoring in developmental periods when mentoring is most needed. Finally, a word as to what the paper does not do may be appropriate here. The paper does not contribute to a better understanding of public programmes for disadvantaged youths, which is a topic left to future research. 


\section{Das Wichtigste in Kürze}

In diesem Beitrag untersuchen wir das Ausmaß und die Entwicklung von Unverbundenheit unter Jugendlichen und jungen Erwachsenen in Deutschland. Unverbundenheit weist mehrere Dimensionen auf. Arbeitslosigkeit, Schulversagen, Beziehungslosigkeit und psychopathologische Stimmungsschwankungen oder Depressionen gehören zu den wichtigeren Dimensionen. Auch in der modernen Volkswirtschaft gibt es Jugendliche, die keine emotionale und finanzielle Unterstützung durch Familie und Freunde erfahren.

Für diese unverbundenen Jugendlichen können zwei Folgeprobleme auftreten. Erstens können aufgrund von unvollständigen Kapitalmärkten zu geringe Bildungsinvestitionen im Jugendalter resultieren, wenn die Familie oder Freunde als Geldgeber ausfallen. Zweitens können diese Jugendlichen den Anschluss an die Gemeinschaft verlieren, wenn es ihnen nicht gelingt, die vielfältigen schulischen und beruflichen Prüfungen abzuschließen, und/oder die geschriebenen und ungeschriebenen Normen und Umgangsregeln der Gesellschaft einzuhalten. Damit kann sich wiederum ein Teufelskreis des Misserfolgs einstellen.

In unserem Beitrag untersuchen wir die Unverbundenheit, die durch Arbeitslosigkeit, Schulversagen und Beziehungslosigkeit zustande kommt. Psychopathologische Angstzustände und Stimmungsschwankungen können wir aufgrund der Datenlage nicht mit einbeziehen. Vielfach ist die letztere Dimension der Unverbundenheit jedoch mit den anderen korreliert.

Aufbauend auf Stichproben aus den Daten des Sozio-Oekonomischen Panels (SOEP) gehören nach unseren Untersuchungen im Mittel 12 Prozent der Jugendlichen während der Altersphase zwischen 17 und 19 Jahren zur Gruppe der unverbundenen Jugendlichen, mit einer leicht steigenden Tendenz in der Periode von 2001 bis 2007. Wir gehen davon aus, dass das Problem der Unverbundenheit unter Jugendlichen mit den SOEP Daten tendenziell unterschätzt wird, so dass die Betroffenheit tatsächlich etwas höher sein könnte.

Aus den Analysen folgt, dass eine widrige Familienumwelt zur Erklärung der Unverbundenheit beiträgt, darunter ein geringes Bildungsniveau der Eltern sowie instabile Familienverhältnisse. Den verantwortlichen Erwachsenen in diesen Familien scheint es nicht zu gelingen, den Jugendlichen emotionalen Rückhalt und finanzielle Zuwendungen in ausreichendem Maße zur Verfügung zu stellen, damit Verbundenheit entstehen kann. Rezessionen tragen mit einer Verzögerung zu einer Zunahme der Unverbundenheit unter Jugendlichen bei. Somit wird auch die aktuelle Wirtschaftskrise den bereits zunehmenden Trend der Unverbundenheit in den folgenden Jahren wahrscheinlich weiter verstärken. Rezessionszeiten tragen dazu bei, dass Wunden aus einer schlimmen Kindheit eher wieder aufbrechen und die Betroffenheit von Unverbundenheit erhöhen, insbesondere dann, wenn Schutzfaktoren fehlen. 


\title{
A socio-economic analysis of youth disconnectedness
}

\author{
Friedhelm Pfeiffer* and Ruben R. Seiberlich ${ }^{+}$ \\ *Centre for European Economic Research, ZEW Mannheim \\ ${ }^{+}$Graduate School of Economics, University of Konstanz
}

Last updated on 30 October 2009

\begin{abstract}
:
According to our research, some $12 \%$ of young people in Germany between the ages of 17 and 19 are disconnected, i.e. not in school, unemployed, and not living with a partner. The percentage of disconnected youths has been on the rise since 2002. There is evidence that an adverse family environment is the most important variable for being disconnected. Early life adversity influences the development of cognitive and noncognitive skills as well as school and labour market outcomes. Macroeconomic factors also contribute to disconnectedness. Recessions are followed by an increase in the number of disconnected youth.
\end{abstract}

Keywords: Disconnected youth, unemployment, school failure, life adversity.

JEL classification: D87, I12, I21, J13

\section{Acknowledgements:}

We gratefully acknowledge support received from the Leibniz Association, Bonn, through its grant "Noncognitive Skills: Acquisition and Economic Consequences". We thank Johannes Gernandt, Lucais Sewell and our colleagues for their valuable comments. Any remaining errors are our own.

\section{Corresponding author:}

Friedhelm Pfeiffer, Centre for European Economic Research (ZEW), P.O. Box 103443, 68034 Mannheim, Germany, Tel.: +49-621-1235-150, E-mail: pfeiffer@zew.de 


\section{Introduction}

Disconnectedness among youth has several dimensions. Failure in school, unemployment and the lack of an intimate relationship as well as developmental disorders are among the most important ones. Many youths in modern society lack networks to provide emotional support, financial assistance, and housing. Two problems for disconnected youths may arise. First, when loans are difficult to obtain due to imperfections in credit markets, insufficient investment in education and human capital can result if family and friends are not available to provide support. Second, integration into society is contingent upon the passage of a number of tests with formal and informal rules. Those who do not pass such tests or who do not adhere to social rules have a higher probability of future failure. This can create a vicious downward spiral. Failure in an apprenticeship training programme, for example, has long-run negative effects on income, increases the likelihood of unemployment, and results in wounds that are far from temporary (Franz et al. 2000).

Despite the extent of this problem, there is a lack of research on the factors responsible for disconnectedness. Does it result from new life events occurring in adolescence? Or does it represent a reopening of old wounds stemming from early life adversity through new adverse life events? Moreover, what factors put adolescents at risk of becoming disconnected? Research on the evolution of disconnectedness and its main determinants in recent decades is scarce in Germany. Economic studies, as a rule, have concentrated on the dimension of unemployment (see Franz, 1982) or on young adults entering the labour market (Franz et al., 2000). Gomez-Salvador and Leiner-Killinger (2008) investigate youth unemployment in the euro area, based on the European Labour Force Survey. According to their findings, youth unemployment in Germany stood at $12.1 \%$ in 2007 , compared to $15.3 \%$ for the entire euro area. The long-term unemployment rate (over one year) for 15-to-24-year-olds was $27 \%$ in 2007. While this number has declined in most countries since 1995, it has increased in Austria, France and Germany.

This paper contributes to the research on disconnected youth in several ways. First, after introducing different concepts of disconnectedness, we investigate how disconnectedness has evolved over a period of more than two decades (from 1984 to 2007) based on samples taken from the German Socio-Economic Panel (SOEP). We focus on those young people who are not employed, not in school and who do not live together with a partner. Our definition of disconnectedness is therefore comprised of economic and social factors. Second, for the years following German reunification, we breakdown the data according to gender, immigrant status and region (East or West), and then compare disconnection and official unemployment rates. Third, we examine individual characteristics as well as family background variables as determinants of disconnectedness, utilising samples taken from the SOEP Youth Questionnaires from 2000 to 2007. In addition, we study the 
association of disconnectedness with sports activities, Rotter's (1966) concept of the "locus of control" and school grades. Sports activities indicate social integration (see Cornelissen \& Pfeifer, 2007; Lechner, 2008; among others) and school grades are a measure of academic success. The locus of control, for its part, measures general beliefs about one's ability to control one's environment and attain goals, and is related to school failure (Coneus et al., 2009; Heckman and Rubinstein, 2001). Occasionally, we compare our results with findings on youth disconnectedness in the United States (Martinez and Wald, 2003; MaCurdy et al. 2006; Fernandes and Gabe, 2009).

Our assessment based on samples from the SOEP reveals that around $12 \%$ of adolescents between the ages of 17 to 19 are disconnected at any one time in Germany. Note that regulations in Germany's dual apprenticeship system contribute to lower unemployment rates in the 17-to-19 age group. In this way, some youth unemployment is delayed until young adulthood in Germany (Franz et al., 2000). A focus on the age group of 17 to 19 years therefore offers a conservative assessment of the prevalence of youth disconnectedness. We find a rising tendency in rates of disconnection after the economic recession of 2001-02. While Martinez \& Wald (2003) also report an increase from 1982 to 2002, according to MaCurdy et al. (2006), the likelihood of suffering from periods of disconnectedness decreased in the United States over the last two decades (before the start of the current recession).

There is only a moderate discrepancy in disconnectedness between males and females, if at all. Compared to our findings, US males have a higher probability of being disconnected, especially black males (MaCurdy et al., 2006; Fernandes \& Gabe, 2009). Furthermore, while youths with immigrant backgrounds have a higher disconnection rate in Germany, this rate has evolved in a manner similar to the entire youth population. Surprisingly, disconnection rates in East Germany were lower than in West Germany in the period after reunification and again after 2004.

Probit estimates using the SOEP Youth Questionnaires confirm that there is no gender difference in disconnection rates. There is also no evidence that an immigrant background per se increases one's probability of becoming disconnected (a finding corroborated by Franz et al., 2000), or that East and West Germans differ. One of the most important variables in our data that increases the probability of being disconnected is a low parental educational level, which confirms the findings of MaCurdy et al. (2006), among others. Another indicator of an adverse family environment that increases disconnectedness is the absence of one or both parents in the first 15 years of development. Thus, our findings seem to confirm that broken homes are associated with higher rates of disconnectedness (see Rasmussen, 2009; and Martinez \& Wald, 2003; among others). If, in addition, parents do not contact teachers during the education of their child, the probability that the child will be disconnected increases. Not contacting teachers can be interpreted as a signal of lower parental interest in school achievement. These findings are in accordance with 
research on the long-term consequences of early life adversity and low responsiveness in families. Early life adversity contributes to lower levels of cognitive and noncognitive abilities at the preschool age, as well as low achievement at the school age (see Blomeyer et al., 2009; Heckman, 2007; among others). Part of disconnectedness in adolescence therefore has deep roots in childhood.

Economic recessions also contribute to youth unemployment, in turn increasing the prevalence of youth disconnectedness. As the current recession is expected to cause a net drop in Germany's 2009 GDP numbers (as well as in most OECD countries), the rate of disconnected youth is likely to increase as a consequence (see also Bell and Blanchflower, 2009; Gomez-Salvador \& Leiner-Killinger, 2008; Verick 2009). In this way, the consequences of job loss, credit market imperfections and a lack of emotional support culminate in periods following recessions.

In sum, disconnectedness seems to result from low-quality adult mentoring in developmental periods when mentoring is most needed. Our concept of disconnectedness takes economic and social factors into account. There are further dimensions and outcomes of disconnectedness. We find a strong correlation between disconnectedness and locus-of-control test results, low school grades and sports activities. Disconnectedness may also be associated with time preferences and developmental disorders. Approximately $20 \%$ of children at the preschool age are impatient in Germany, or have a bias for the present (Bartling et al. 2009). Mood and anxiety disorders seem to be widespread (affecting approximately $20 \%$ of the population, see Laucht et al., 2009). Future research is necessary to investigate the relationship between mood and anxiety disorders, time preferences and our concept of disconnectedness more deeply.

Since we only use relatively small samples of young individuals from the SOEP, some of our findings should not be generalised. Presumably, the magnitude of the problem of disconnected youth is underestimated due to survey bias: we can assume that the families of disconnected youths participate in the SOEP less frequently. Although the SOEP gathers data on a number of relevant socio-economic factors that contribute to disconnectedness, an equally large number remains unobserved, such as overcrowding, violence and other aspects of environmental adversity.

Finally, a word as to what the paper does not do may be appropriate here. The paper does not contribute to an understanding of public programmes dedicated to helping disadvantaged youths. Surprisingly enough, in spite of many government efforts to assist disadvantaged adolescents, the problem of disconnectedness is still present in many countries. As MaCurdy et al. (2006) note, "Despite the billions of federal, state local and private dollars spent on a wide range of programs aimed at helping disadvantaged youth, many still experience 'disconnection' leading them to fail in acquiring the skills necessary for establishment as independent adults.” 
The rest of this paper is organised as follows. Section 2 introduces the data and elucidates disconnectedness. Section 3 examines the evolution of disconnectedness from 1984 to 2007. Section 4 presents a breakdown of disconnectedness by gender, immigrant status and region for the period after German reunification. Section 5 studies individual determinants of disconnectedness and its association with school grades, youth locus of control and sports activities. Section 6 offers concluding remarks.

\section{Data and concepts of disconnectedness}

Different samples taken from the German Socio-Economic Panel (SOEP) are used in this study. The SOEP is a representative national longitudinal data set which has surveyed households and individuals (Wagner et al., 2007) on socio-economic issues since 1984. In 2007, some 11,000 households comprising more than 20,000 persons were sampled by the SOEP. We first generate a sample of young people between the ages of 17 and 25 to investigate the evolution of four different concepts of disconnectedness, and compare the results with findings from the United States (Sample A). Next we focus on adolescents aged 17 to 19 for an analysis of disconnectedness according to gender, immigrant status and region (East or West Germany) (Sample B). This analysis covers the period from 1991 to 2007 (in a unified Germany). Note that in this period the German economy suffered two major recessions, one in 1993-95 and one in 2001-03. In a third step, determinants of disconnectedness and other socio-economic outcomes are analysed on the basis of predetermined variables (Sample C). Sample $C$ is taken from the SOEP Youth Questionnaires introduced in 2000. It consists of one 17-year-old household member for each household that participated in the survey in the years 2000 to 2007.

Disconnectedness has several dimensions, and we focus on unemployment, nonenrolment in school and lack of an intimate relationship. First we elucidate two concepts of disconnectedness introduced by MaCurdy et al. (2006), and then add two additional ones. Table 1 summarises the four concepts of youth disconnectedness, which are referred to as DC1, DC2, DC3 and DC4. The concepts have a clear hierarchy. DC1 covers two dimensions, and an additional dimension is added at each step (i.e. DC2 has three dimensions; DC3, four dimensions; and DC4, five dimensions).

In DC1, the first concept, not being enrolled in school and not working constitutes disconnectedness. MaCurdy et al. (2006) find that $24 \%$ of all youths growing up in the United States experience at least one year of not working and not being enrolled in school by the age of 22. If the condition not living with a spouse is added (DC2) they estimate that $19.8 \%$ of all youths accumulate at least one year of disconnectedness, and $8.7 \%$ accumulate at least two years. Teen mothers, highschool dropouts, youths who have been convicted of a crime, and youths who spent time not living with their parents are overrepresented in this group. In the third 
concept, DC3, not living together with a partner is substituted for not living together with a spouse. Partners, and not only spouses, may provide financial and emotional support (Martinez \& Wald, 2003). According to DC4, an individual is disconnected if he or she, in addition to lacking a partner, fulfils the remaining four criteria.

Table 1: Four concepts of disconnectedness

\begin{tabular}{lcccc}
\hline \hline & DC1 & DC2 & DC3 & DC4 \\
\hline Not Enrolled in School and Not Working & $\mathrm{X}$ & $\mathrm{X}$ & $\mathrm{X}$ & $\mathrm{X}$ \\
Not Enrolled in School, Not Working, and Not Living with a Spouse & & $\mathrm{X}$ & $\mathrm{X}$ & $\mathrm{X}$ \\
Not Enrolled in School, Not Working, and Not Living with a Partner & & & $\mathrm{X}$ & $\mathrm{X}$ \\
Not Enrolled in School, Not Working, and Not Having a Partner & & & & $\mathrm{X}$ \\
\hline \hline
\end{tabular}

These concepts are used to sort the SOEP data. If respondents report that they are not employed, in school, or receiving vocational training, they are categorised as DC1. If they also report that they are not married, DC2 is used instead. The SOEP's marital-status question has changed over time. With the exception of 1985, the SOEP asked whether respondents live together with a partner (i.e. in a serious longterm relationship). We use the answer to this question to determine a subject's DC3 status. In 1991, the question was modified again, and split into two questions: participants were asked if they were in a long-term relationship, and then if they lived together with their partner. DC4 is thus available from 1991 onward.

\section{The evolution of disconnectedness between 1984 and 2007}

Figure 1 shows the evolution of our four concepts of disconnectedness based on Sample A from 1984 to 2007. Four conclusions emerge. First, the four concepts have a clear hierarchy and are highly correlated (see Table 2). Disconnection rates range from 4\% (DC4) to 16\% (DC1) (in 1994, for example). Second, the evolution of disconnectedness depends on the concepts chosen. According to DC1, the rate of disconnectedness decreases slightly between 1984 and 2007. This seems to be in line with the findings of MaCurdy et al. (2006) and Franz et al. (2000). The German youth unemployment rate declined until 1990, as the supply of apprenticeship positions was larger than the demand for them.

However, DC2, DC3 and DC4 increase after 1992 and again after 2002. This is because the decline in the proportion of youths in a relationship and living with a partner or a spouse offset the rise of the number of youths not in school and unemployed. Third, the cyclical movement of the disconnection rates mirror one another. It turns out that disconnection follows the unemployment rate but with a time lag. The correlation between DC3 and the lagged unemployment rate amounts to 0.46 in the time period under investigation (Table 2). Economic recessions contribute to youth unemployment, in turn increasing the prevalence of youth disconnectedness (see also Bell and Blanchflower, 2009; Gomez-Salvador \& LeinerKillinger, 2008; Verick 2009). The consequences of job losses, credit market 
imperfections and a lack of emotional support culminate in periods following recessions.

Figure 2 illustrates the evolution of disconnection with the same concepts, this time for females only. Two conclusions emerge. On the one hand, the DC1 disconnection rate is much higher for females from 1984 to 2000, which is in line with the findings of MaCurdy et al. (2006) as well as Fernandes \& Gabe (2009). On the other hand, disconnectedness among females seems to be lower than among males for the other three concepts. Females are more often unemployed and not in school. However, they live together with a spouse or partner more often. Second, the gender gap decreases over time irrespective of the concepts examined. According to our understanding, this is part of an overall trend toward higher female participation rates in the labour market. Female labour market participation increased from $45.9 \%$ in 1968 to 63.6\% in 2002 (Alda et al., 2005: 97). Since employment participation is not our research focus we will disregard DC1 in what follows.

Figure 1: The evolution of disconnectedness, 1984-2007

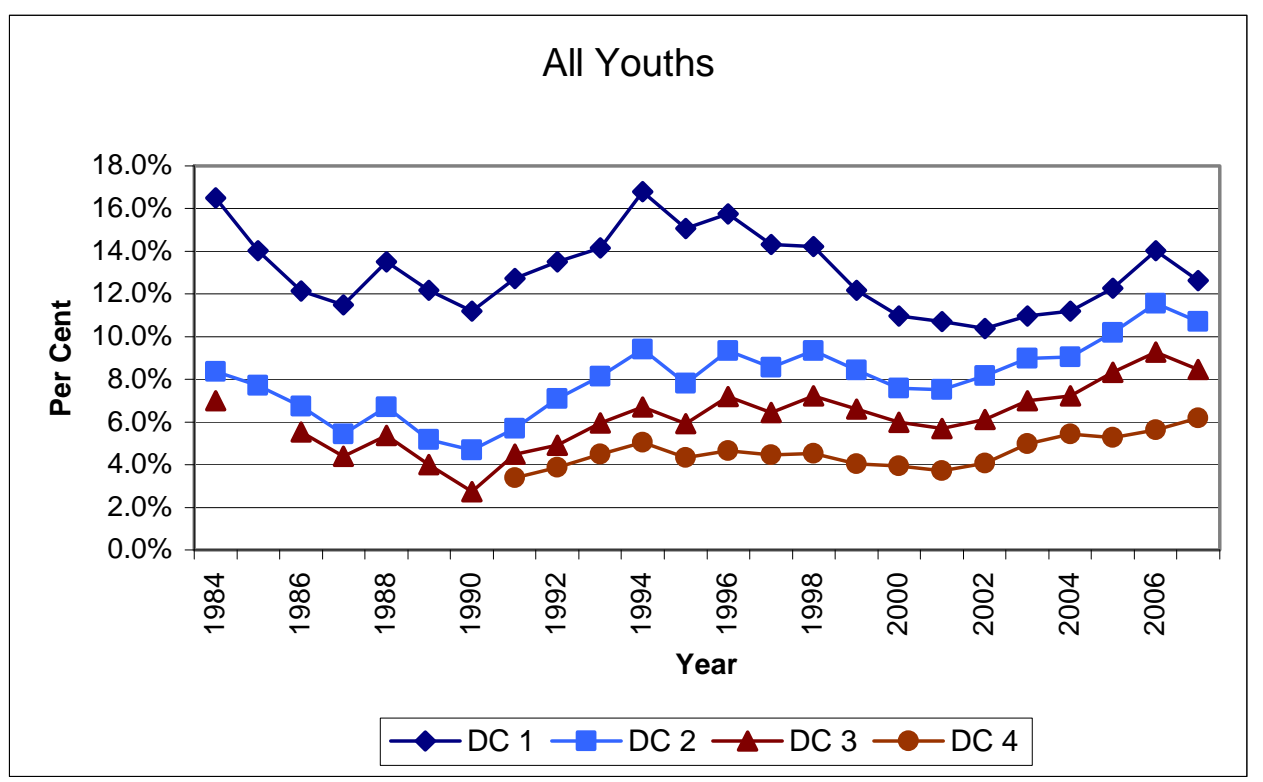

Source: Sample A from SOEP, 1984-2007; own calculations (DC3 not available in 85, DC4 since 91).

Table 2: Correlations among the concepts and the lagged unemployment rate

\begin{tabular}{ccccc}
\hline & DC1 & DC2 & DC3 & DC4 \\
\hline DC2 & 0.94 & & & \\
DC3 & 0.90 & 0.99 & & \\
DC4 & 0.85 & 0.92 & 0.91 & \\
Unemployment (t-1) & 0.19 & 0.41 & 0.46 & 0.27 \\
\hline
\end{tabular}

Source: Sample B of 17-to-19 year old respondents from SOEP, 1991-2007; yearly official unemployment rates (statistics from the German Federal Labour Office); own calculations. 
DC2, DC3, and DC4 evolve similarly. We will focus on DC3 for two reasons. First, living together with a partner is a well accepted alternative to living with a spouse in modern German society. The share of unmarried couples who live together, for instance, increased by 34\% from 1996 to 2007 (Destatis, 2008). Second, DC3 moves in accordance with DC2 and DC4 and always remains in between the two. Since the correlation rates are 0.9 or higher (see Table 2), a detailed examination of one concept is sufficient for the purpose of our investigation.

Figure 2: The evolution of female disconnectedness, 1984-2007

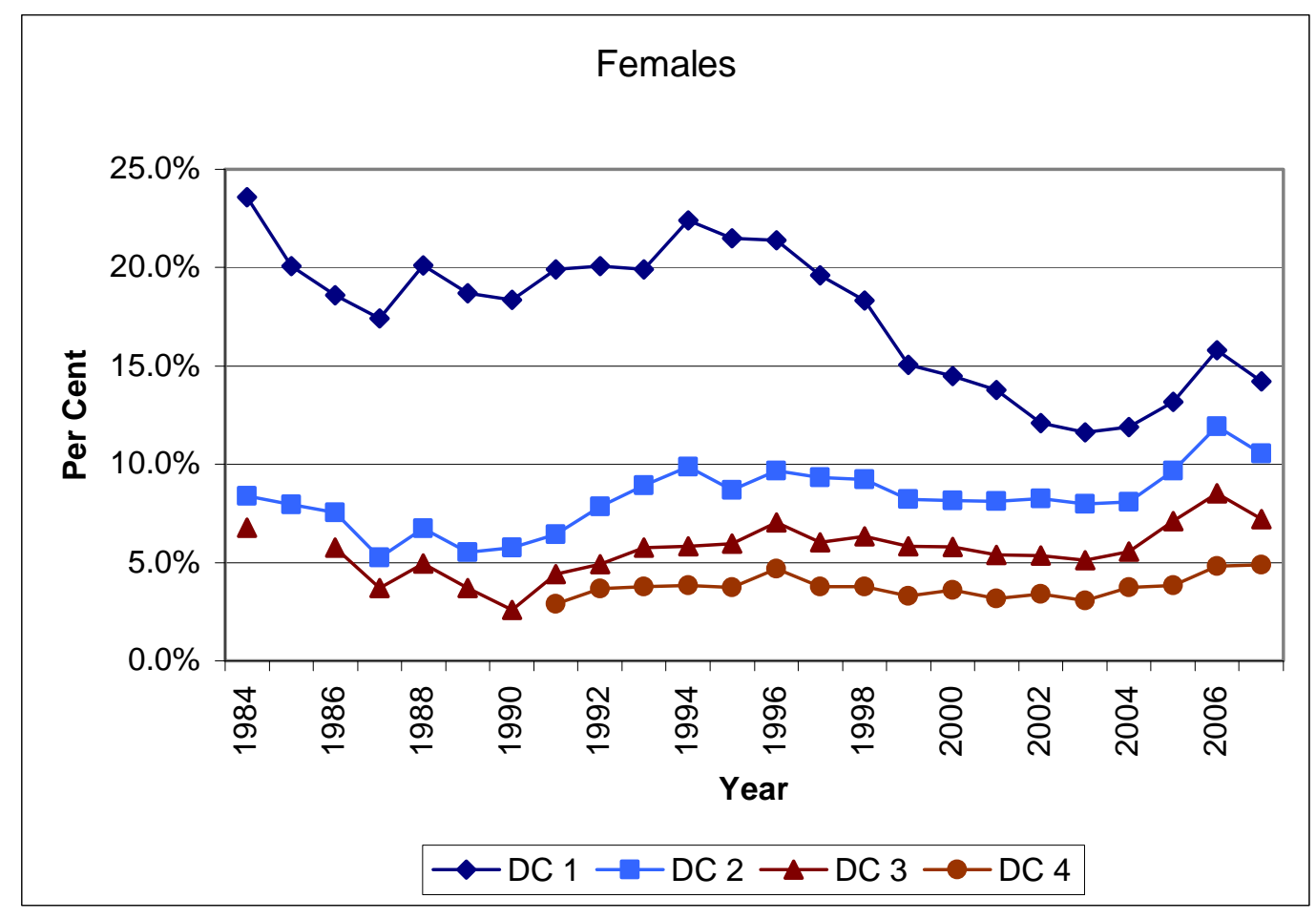

Source: Sample A from SOEP 1984-2007, own calculations (DC3 not available in 85, DC4 since 91).

\section{Breakdown of disconnectedness}

Figure 3 examines the evolution of disconnectedness (DC3) in samples with different age restrictions since 1991 (Sample B), together with official youth unemployment rates. We compare the age group of 17 to 25 with the subsamples of disconnected youth in the age group of 17 to 19. The former age group constitutes Sample A. Three findings emerge. First, and not surprisingly, the disconnection rate of the 17-to-19-year-olds in each year lies below the disconnection rate of the 17-to25-year-olds. This confirms the findings of Franz et al. (2000). The German dual apprenticeship system contributes to lower unemployment rates among teenagers at the expense of delaying the onset of unemployment to young adulthood. Second, the disconnection rates move in a similar way over time. For adolescents (17 to 19), the rate increased from $4.2 \%$ in 1991 to $7.4 \%$ in 2007 and for the whole sample the rate increased from $4.5 \%$ to $8.5 \%$. Third, official unemployment rates and our measure 
of disconnectedness among adolescents move in a different way. While official unemployment rates decreased from 1997 to 2004, our disconnection rates increased slightly. Clearly, social factors - not just economic ones - influence disconnectedness. Both of these dimensions are important in their own right.

To restrict the sample to adolescents, we focussed on a relevant age group. Table 3 contains the transition matrix for 18-or-19 year olds who were disconnected at time $t$ and again at age 20 or 21 at $t+2^{1}$ between 1991 and 2007. A statistical test for disconnectedness rates $t, t+2$ clearly rejects the null hypothesis of equality for these rates (1\% significance). Adolescents who are disconnected at the age of 18 or 19 have a probability of being disconnected two years later that is 15 percentage points higher than those who are not disconnected at 18 or 19.

Figure 3: The share of disconnected youth (DC3) compared to youth unemployment rates, 1991-2007

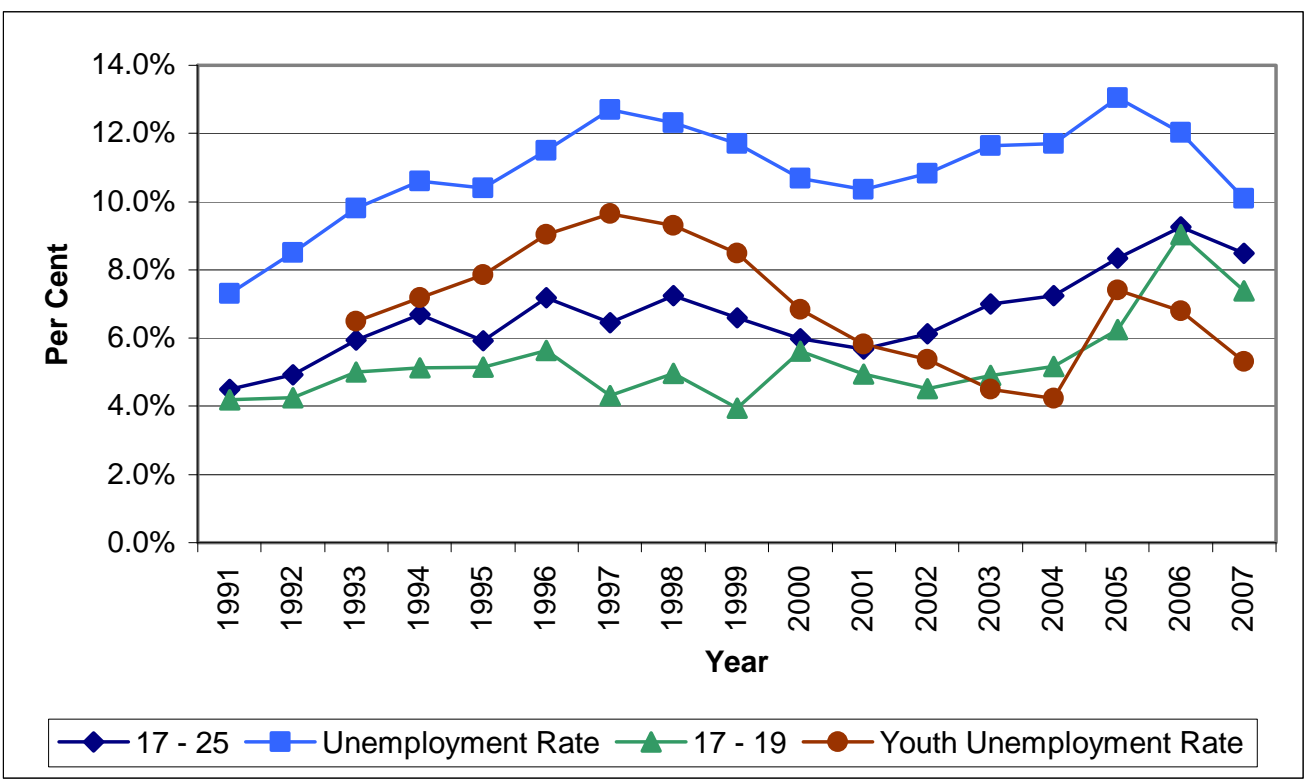

Source: Sample B from SOEP, 1991-2007; own calculations; Federal Labour Office statistics.

Table 3: Transition matrix $\mathrm{t}, \mathrm{t}+2$

\begin{tabular}{|c|c|c|c|}
\hline \multicolumn{4}{|c|}{$D C$ in $t+2$} \\
\hline $\mathrm{DC}$ in $\mathrm{t}$ & $\mathbf{0}$ & 1 & Total \\
\hline 0 & 2,792 & 278 & 3,070 \\
\hline$\%$ & $90.9 \%$ & $9.1 \%$ & $100.0 \%$ \\
\hline 1 & 124 & 39 & 163 \\
\hline$\%$ & $76.1 \%$ & $23.9 \%$ & $100.0 \%$ \\
\hline Total & 2,916 & 317 & 3,233 \\
\hline
\end{tabular}

Source: Sample B from SOEP 1991-2007, own calculations

\footnotetext{
${ }^{1}$ We choose $t+2$ (instead of $t+1$ ) to ensure that an individual appears only once in the sample. See Table A1 in the appendix for the transition matrix $\mathrm{t}, \mathrm{t}+3$ of the 17-, 18- and 19-year-olds. We employ the transition matrix of the 18and 19-year-olds since this reduces missing values by 30 percentage points, Table A2.
} 
Three findings arise from a more detailed breakdown of disconnectedness. First, the difference in the DC3 disconnection rate between females and males is only moderate, if existent at all (Figure 4), which seems to be in line with MaCurdy et al. (2006). Second, youth with immigrant backgrounds have by and large a higher risk of becoming disconnected in Germany (Figure 5), as well as in the United States (Martinez and Wald 2003, MaCurdy et al. 2006 and Fernandes and Gabe 2009). The difference varies with the business cycle and seems to be lower in economic upturns.

Figure 4: Disconnectedness (DC3) among males and females

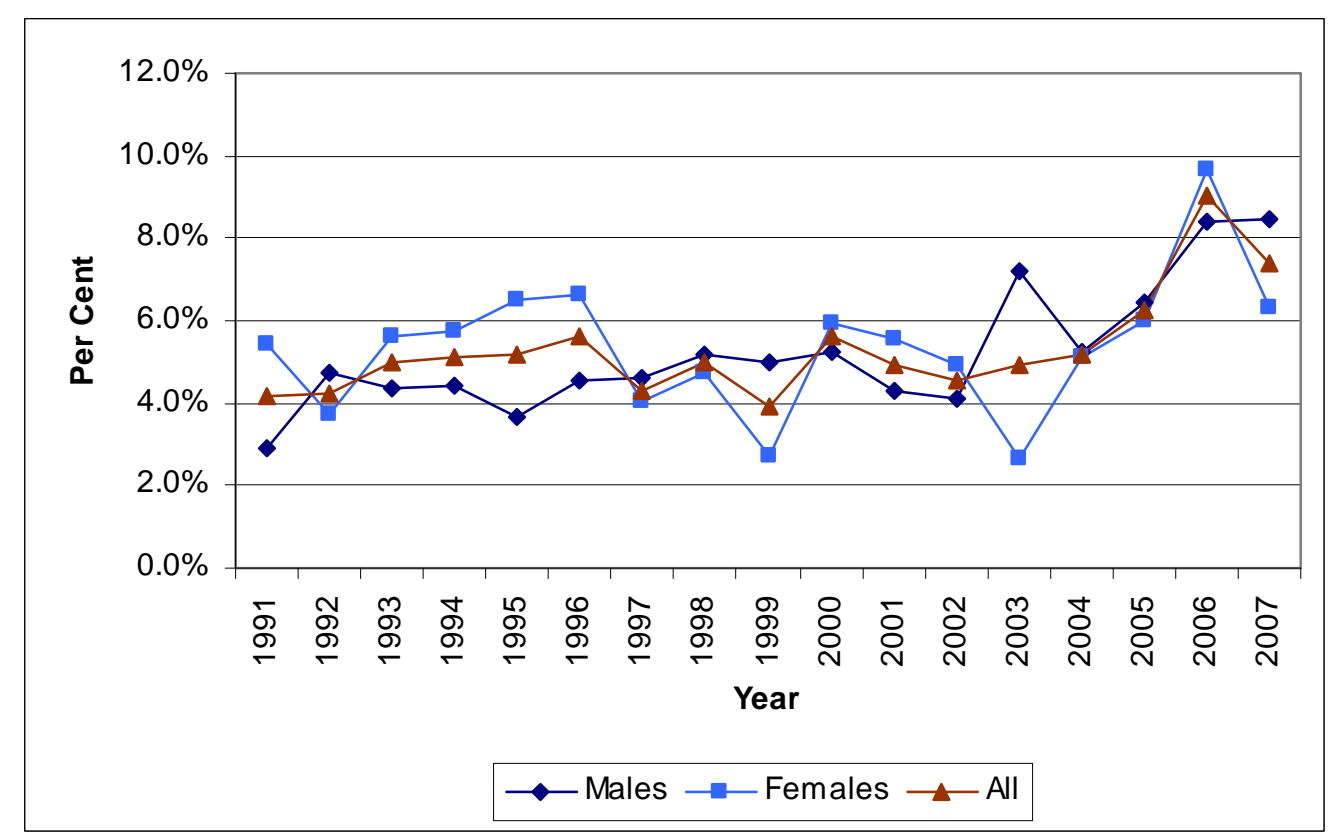

Source: Sample B from SOEP, 1991-2007; own calculations.

Third, and surprisingly, youth disconnectedness has been less prevalent in East than in West Germany, with the exception of the period from 2001 to 2004 (Figure 6). This is true despite the fact that youth unemployment rates are higher in the East (14.4\% in 2007) than in the West (6.9\%) (German Federal Labour Office, 2008). Lower rates of disconnectedness in East Germany are partly an inheritance of the culture of early independence that characterised life in communist East Germany. East German youths marry sooner, start their own families earlier and are therefore more independent from their parents than their West German counterparts (see Montada and Oerter 2002, 320). Another reason is that the share of youth with immigrant background is lower in East compared to West Germany. 
Figure 5: Disconnectedness (DC3) among immigrants and Germans

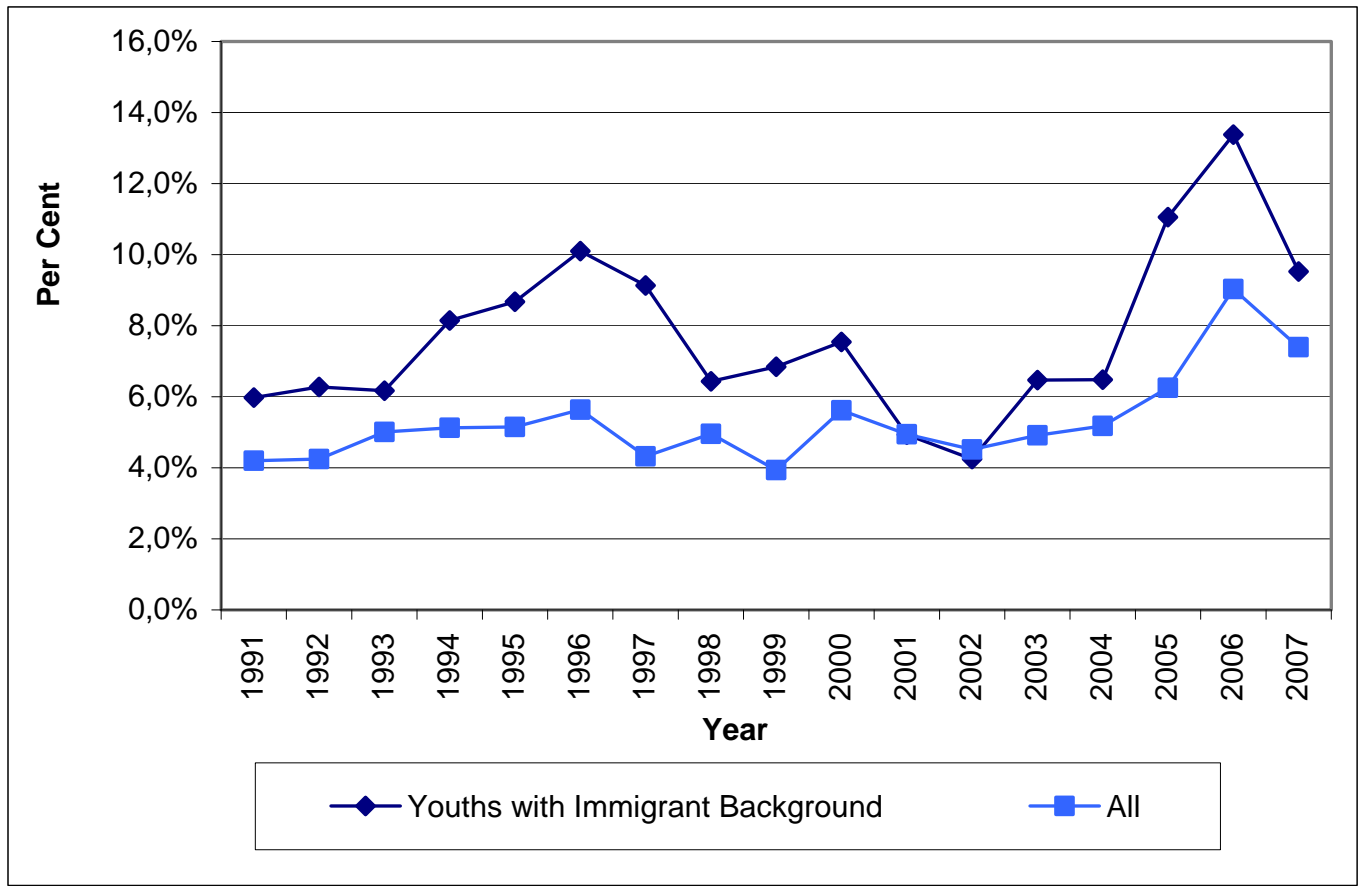

Source: Sample B from SOEP, 1991-2007; own calculations.

Figure 6: Disconnectedness (CD3) among East and West Germans

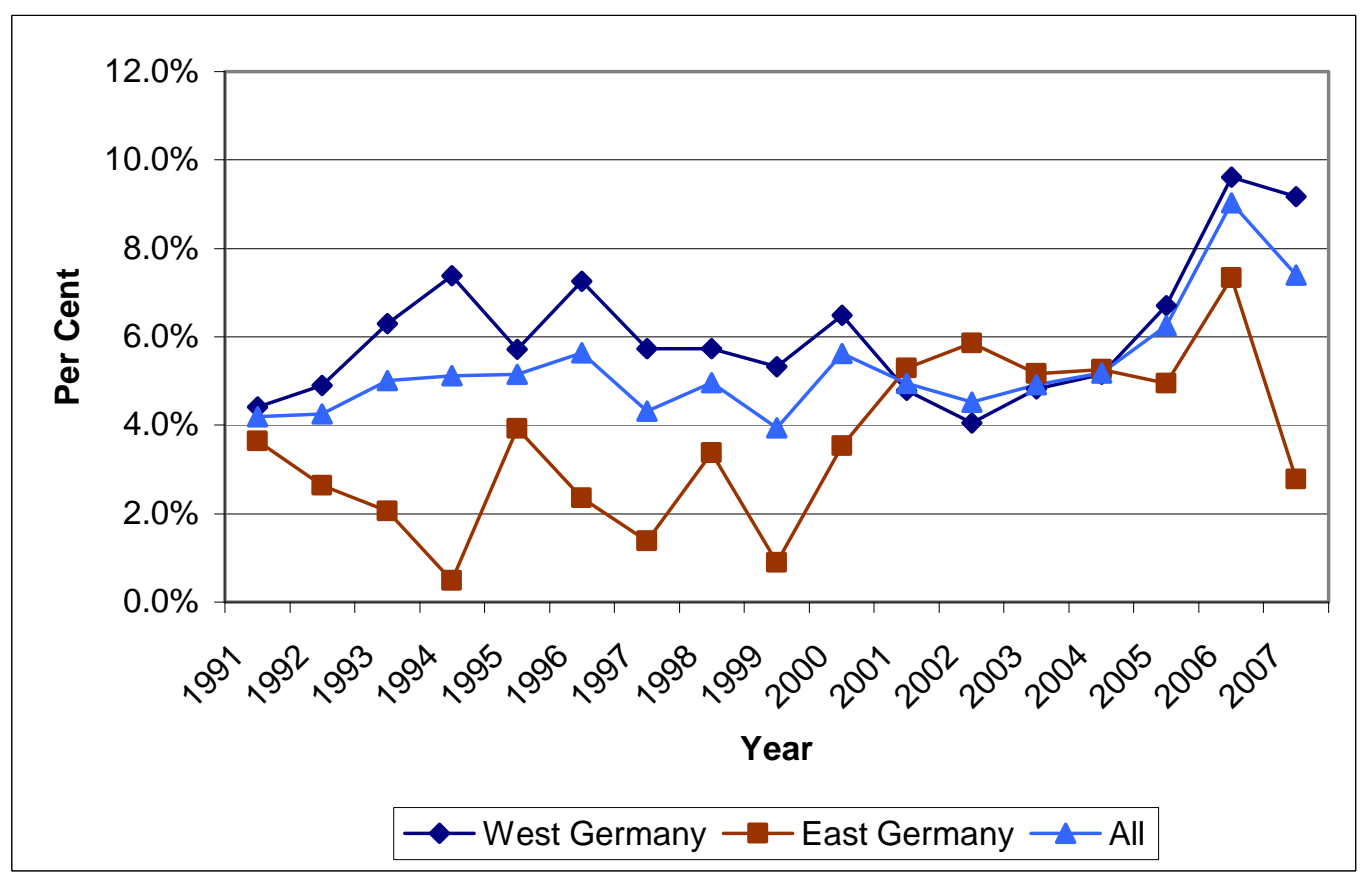

Source: Sample B from SOEP, 1991-2007; own calculations. 


\section{Determinants of disconnectedness and related outcomes}

Individual determinants of disconnectedness (DC3) are examined based on Sample $C$, taken from the SOEP Youth Questionnaire (2000-2007). DC3 equals 1 if a person is unemployed, not enrolled in school and not living together with a partner at the age of 17,18 or 19; otherwise, it is 0 . Siblings are excluded and only one adolescent from each household is examined to avoid composition effects. These restrictions leave us with 1,042 individuals, 522 females and 520 males. Disconnectedness in Sample C hovers around $12 \%$ and increases over time (Table 4, a).

Table 4: The relationship between disconnectedness and other outcomes

\begin{tabular}{|c|c|c|c|c|c|c|c|c|c|}
\hline \multicolumn{10}{|c|}{ a) Disconnectedness of 17-year-olds, 2000-2005, and by sex in \% } \\
\hline DC3 & All & Males & Females & 2000 & 2001 & 2002 & 2003 & 2004 & 2005 \\
\hline $\mathbf{0}$ & 87.8 & 88.5 & 87.2 & 88.9 & 93.9 & 90.2 & 84.9 & 86.8 & 86.4 \\
\hline 1 & 12.2 & 11.5 & 12.8 & 11.1 & 6.1 & 9.8 & 15.1 & 13.2 & 13.6 \\
\hline Total & 100 & 100 & 100 & 100 & 100 & 100 & 100 & 100 & 100 \\
\hline \multicolumn{10}{|c|}{ b) Other Outcomes } \\
\hline & & & Min & Max & Mean & DC3 0 & DC3 1 & t-Test & \\
\hline & & Grade & 1 & 6 & 3.0 & 2.9 & 3.2 & $\mathrm{t}=-4.1$ & \\
\hline & & Rotter & 23 & 63 & 45.5 & 45.7 & 43.5 & $\mathrm{t}=3.4$ & \\
\hline & & Sport & 0 & 4 & 2.5 & 2.5 & 1.9 & $t=5.3$ & \\
\hline
\end{tabular}

Source: Sample C taken from SOEP Youth Questionnaire, 2000-2007; own calculations.

There is paucity of research on the relationships between disconnectedness and other outcomes. We therefore study the relationship between the occurrence of DC3 and average school grades, sports activities and Rotter's (1966) locus of control. The locus of control measures general beliefs about one's capacity to influence one's environment and achieve goals. "Internalisers" tend to attribute outcomes to their actions, whereas "externalisers" attribute outcomes to outer circumstances. The intensity of sports activities, Sports, is constructed such that 0 means never; 1 , less than once a month; 2, once a month; 3 , once a week; and 4, daily sports activities.

Table 4b demonstrates that the group of disconnected youth on average perform significantly worse in school (note that in the German educational system, 1 is the best and 6 the worst grade), participate in sports activities less frequently and have lower locus of control scores. Being disconnected thus goes hand in hand with a tendency to externalise (confirming Coneus at al. 2009, who show that lower locus of control scores are related to school failure). Some studies argue that a lower locus of control is related to lower noncognitive skills, such as lower levels of selfdiscipline or perseverance (Heckman and Rubinstein, 2001). If this interpretation is correct, our findings demonstrate that lower levels of self-discipline and disconnectedness are related. 
Participation in sports activities indicates social integration and a concern for physical as well as mental health. For many people in the industrialised world, physical activities are no longer necessary for survival. Individuals require initiative to engage in activities that improve health and well-being. Sports activities may contribute to productivity or improve achievement at school and is awarded by the labour market. Lechner (2008) estimates the rate of labour market returns for investments in sport activities at 5\% to 10\%. Cornelissen \& Pfeifer (2007) find that the chances of obtaining a university degree, as opposed to a vocational qualification or no professional degree, due to sports increase by about $5.3 \%$ for men, and $4.7 \%$ for women.

In the next step a multivariate statistical analysis is performed to investigate the significance of the determinants of disconnectedness (Table 5). We concentrate on predetermined variables only. As predictor variables we include a gender dummy variable, female, West, which equals 1 if the youth is from West Germany; immigrant, which equals 1 if the youth has an immigrant background; and the age of the mother at the time of birth, age of the mother. In addition, a set of dummy variables for the educational level of the parents is included; for whether the individual lived during the first 15 years with both parents; whether the parents are concerned about the school performance of their offspring or not; and whether the individual had to repeat one or more classes in his or her school history.

Table 5: Descriptive statistics and tests

\begin{tabular}{ccccc}
\hline \hline Variable [co-domain] & All & Connected & Disconnected & Test St. \\
\hline female [0,1] & $50.1 \%$ & $49.7 \%$ & $52.8 \%$ & $\mathrm{z}=-0.6$ \\
West [0,1] & $72.0 \%$ & $70.8 \%$ & $80.3 \%$ & $\mathrm{z}=-2.2$ \\
immigrant [0,1] & $19.0 \%$ & $17.8 \%$ & $27.6 \%$ & $\mathrm{z}=-2.6$ \\
low education father [0,1] & $35.1 \%$ & $33.2 \%$ & $48.8 \%$ & $\mathrm{z}=-3.5$ \\
medium education father [0,1] & $31.9 \%$ & $32.0 \%$ & $30.7 \%$ & $\mathrm{z}=0.3$ \\
high education father [0,1] & $21.8 \%$ & $23.3 \%$ & $11.0 \%$ & $\mathrm{z}=3.1$ \\
low education mother [0,1] & $27.9 \%$ & $25.6 \%$ & $44.9 \%$ & $\mathrm{z}=-4.5$ \\
medium education mother [0,1] & $43.3 \%$ & $44.2 \%$ & $37.0 \%$ & $\mathrm{z}=1.5$ \\
high education mother [0,1] & $17.8 \%$ & $19.0 \%$ & $8.7 \%$ & $\mathrm{z}=2.9$ \\
age of the mother [17,48] & 27.3 & 27.3 & 27.5 & $\mathrm{t}=-0.4$ \\
first 15 years not with both parents [0,1] & $21.7 \%$ & $20.7 \%$ & $29.1 \%$ & $\mathrm{z}=-2.2$ \\
parents do not contact teacher [0,1] & $9.2 \%$ & $8.4 \%$ & $15.0 \%$ & $\mathrm{z}=-2.4$ \\
class repeated [0,1] & $21.7 \%$ & $20.1 \%$ & $33.1 \%$ & $\mathrm{z}=-3.3$ \\
\hline \hline
\end{tabular}

Source: Sample C, 1,042 observations taken from the SOEP Youth Questionnaire, 2000-2007; own calculations

There are significant differences in some of these variables among the disconnected and connected youth (Table 5) and none in others. For the dummy variables a test of equal proportion was performed, and for the continuous variable age of the mother a t-test. These tests suggest that there are more youths with immigrant backgrounds and in West Germany in the group of disconnected youth. There seems to be no 
difference among males and females and among youth with mothers of different ages. However, disconnected youths more often have parents with a low level of education and have more often repeated a class at least once. Moreover, disconnected youths grow up less often with both parents or receive less supervision and support from parents in the form of teacher contacts.

A multivariate analysis (Table 6) partly reveals new results and partly confirms the descriptive ones.

Table 6: Findings of the multivariate analysis

\begin{tabular}{|c|c|c|c|c|}
\hline \multirow[b]{2}{*}{ Variables } & \multicolumn{2}{|c|}{ Probit: Disconnectedness } & \multicolumn{2}{|c|}{ OLS: Rotter } \\
\hline & Marg. effects & z-Values & Coefficient & t-Values \\
\hline female & 0.0169 & 0.87 & 0.2696 & 0.62 \\
\hline West & 0.0300 & 1.19 & 1.0373 & 1.82 \\
\hline immigrant & 0.0161 & 0.60 & 0.7664 & 1.21 \\
\hline medium education father & 0.0041 & 0.16 & 1.0597 & 1.81 \\
\hline high education father & -0.0530 & -1.88 & 1.0745 & 1.63 \\
\hline medium education mother & -0.0303 & -1.27 & 0.7780 & 1.36 \\
\hline high education mother & -0.0637 & -2.12 & 1.9105 & 2.61 \\
\hline age of the mother & 0.0024 & 1.28 & 0.0171 & 0.38 \\
\hline first 15 years not with both parents & 0.0485 & 2.00 & -1.0381 & -1.97 \\
\hline parents do not contact teacher & 0.0582 & 1.69 & -0.4535 & -0.60 \\
\hline class repeated & 0.0673 & 2.75 & -1.3051 & -2.46 \\
\hline \multirow[t]{4}{*}{ Constant } & - & - & 41.5987 & 24.56 \\
\hline & Obs. & 1,042 & Obs. & 1,042 \\
\hline & Pseudo R² & 0.07 & Adj. $R^{2}$ & 0.04 \\
\hline & LR & 51.77 & F-statistic & 2.68 \\
\hline & \multicolumn{2}{|c|}{ OLS: Average Grade } & \multicolumn{2}{|c|}{ OLS: Sport } \\
\hline Variables & Coefficient & t-Values & Coefficient & t-Values \\
\hline female & -0.1658 & -3.91 & -0.3928 & -4.94 \\
\hline West & 0.2021 & 3.63 & 0.1608 & 1.54 \\
\hline immigrant & -0.0031 & -0.05 & 0.1043 & 0.90 \\
\hline medium education father & 0.0077 & 0.13 & -0.0757 & -0.71 \\
\hline high education father & -0.0637 & -0.99 & 0.2882 & 2.39 \\
\hline medium education mother & -0.0644 & -1.16 & 0.2265 & 2.17 \\
\hline high education mother & -0.1238 & -1.72 & 0.3453 & 2.57 \\
\hline age of the mother & -0.0021 & -0.47 & -0.0055 & -0.67 \\
\hline first 15 years not with both parents & 0.0434 & 0.84 & -0.1882 & -1.95 \\
\hline parents do not contact teacher & 0.0269 & 0.37 & -0.1075 & -0.78 \\
\hline class repeated & 0.4176 & 8.04 & -0.1264 & -1.30 \\
\hline \multirow[t]{4}{*}{ constant } & 2.9063 & 21.11 & 2.5432 & 9.85 \\
\hline & Obs. & 1,042 & Obs. & 1,042 \\
\hline & Adj. $\mathrm{R}^{2}$ & 0.11 & Adj. $\mathrm{R}^{2}$ & 0.06 \\
\hline & F-statistic & 12.13 & F-statistic & 5.76 \\
\hline
\end{tabular}

Source: Sample C, SOEP 2000-2007, own calculations; the equations for the Rotter score and disconnectedness include year dummies, not reported here. 
First, a lower parental educational level significantly contributes to increased disconnectedness. If the mother has a high educational level the probability of being disconnected is reduced by $6.4 \%$. In addition, it decreases by $5.3 \%$ if the father is also highly educated, a finding that confirms the German government's Youth Report (Deutscher Bundestag, 2009) and the literature (MaCurdy et al., 2006; among others). There seems to be no significant difference among youths whose parents have a low or medium educational level. Furthermore, family presence until the age of 15 and parent contact with teachers contribute significantly to connectedness. Second, neither the region of residence in Germany nor an immigrant background significantly impact the probability of being disconnected. The latter result is in line with Franz et al. (2000), who find no evidence for discrimination against foreign youths in the labour market. It also confirms Aldashev et al. (2009), who demonstrate that language skills and not an immigrant background per se contribute to lower earnings among immigrants in Germany.

The remaining outcome equations reveal further conclusions. First, the educational level of the father retains its explanatory power for sports and the locus of control. However it no longer has significant relevance for school grades. This suggests that school grades are determined to a stronger degree by the mother's as opposed to the father's educational level. Second, having repeated a class becomes the quantitatively most important variable for bad school grades. Third, females perform better than males and East Germans better than West Germans in school grades. Fourth, males significantly more often participate in sports compared to females. Fifth, family presence does not significantly influence school grades or sports activities. However, a significant positive association with the locus of control score cannot be rejected. Hence, the locus of control and disconnectedness seem to measure outcomes that are determined by similar socio-economic background characteristics.

To sum up the empirical findings from the SOEP Youth Questionnaire, having lowskilled parents, absent parents and parents who do not contact teachers are among the relevant variables that predict disconnectedness. The findings demonstrate the prominent role of adverse family environments for development (see also Blomeyer et al., 2009) compared to the region of residence or an immigrant background.

\section{Conclusions}

In this paper we investigated the prevalence of "disconnectedness" among German youth. Youth disconnectedness can have several dimensions. Unemployment, failure in school, the lack of an intimate relationship and developmental disorders are among the most important ones. Many youths in modern society lack networks to provide emotional support, financial assistance and housing.

Two problems for disconnected youths may arise. First, when loans are difficult to obtain due to imperfections in credit markets, insufficient investment in education 
and human capital can result if family and friends are not available to provide support. Second, integration into society is contingent upon the passage of a number of tests with formal and informal rules. Those who do not pass such tests or who do not adhere to social rules have a higher probability of future failure. This can create a vicious downward spiral.

The definition of disconnectedness used in our paper is based on economic and social factors. A disconnected individual is one who is not working, not enrolled in school and not living together with a partner. While there is often a correlation between disconnectedness and anxiety or mood disorders, an investigation with the psychological dimension of disconnectedness is left for future research.

Around $12 \%$ of young people between the ages of 17 and 19 are disconnected according to our definition. This figure has been on the rise since 2002. There is evidence that an adverse family environment is the most important variable for being disconnected at 17-to-19 years of age. While there is no evidence that an immigrant background contributes per se to disconnectedness, adolescents with an immigrant background are overrepresented among the disconnected. Disconnectedness seems to stem from having parents with a low educational level and/or from living in a broken home. Parents in such families have difficulty providing emotional and material support for their offspring in times of developmental change as well as in times of economic hardship.

We have found evidence that economic downturns contribute to disconnectedness with a delayed effect. Following a recession, the most disadvantaged youths seem to suffer most, presumably because recessions aggravate the wounds left from early life adversity. Our results suggest that the current economic crisis will result in an increase in youth disconnectedness in the coming years.

In sum, disconnectedness seems to result from low-quality adult mentoring in developmental periods when mentoring is most needed. Although our findings are corroborated by international research, the shortcomings of our study should be mentioned. Since we only use relatively small samples of young individuals from the SOEP, not all findings can be generalised. It is fair to assume that the prevalence of youth disconnectedness is underestimated in our samples. 


\section{References}

Alda, H., M. Baethge, P. Bartelheimer, and L. Bellmann et al. (2005), Berichterstattung zur sozioökonomischen Entwicklung in Deutschland - Arbeit und Lebensweisen. VS Verlag für Sozialwissenschaften/GWV Fachverlag GmbH, Wiesbaden.

Aldashev, Alisher, Johannes Gernandt and Stephan L. Thomsen (2009), Language Usage, Participation, Employment and Earnings - Evidence for Foreigners in West Germany with Multiple Sources of Selection, Labour Economics 16, 330341.

Bartling, Björn, Ernst Fehr, Barbara Fischer, Fabian Kosse, Michel Maréchal, Friedhelm Pfeiffer, Daniel Schunk, Jürgen Schupp, C. Katharina Spieß and Gert G. Wagner (2009), Zeitpräferenzen von Kindern im Vorschulalter: Eine experimentelle Untersuchung im Rahmen des Sozio-oekonomischen Panels (SOEP), SOEPpapers on Multidisciplinary Panel Data Research No. 203, Berlin.

Bell, David N.F. and David G. Blanchflower (2009), What Should Be Done About Rising Unemployment in the OECD? IZA Discussion Paper 4455, Bonn.

Blomeyer, Dorothea, Katja Coneus, Manfred Laucht and Friedhelm Pfeiffer (2009), Initial Risk Matrix, Home Resources, Ability Development and Children's Achievement, Journal of the European Economic Association 7(2-3), 638-648.

Bundesagentur für Arbeit (2008), Arbeitsmarkt 2007, Amtliche Nachrichten der Bundesagentur für Arbeit, 56. Jahrgang, Sondernummer 2.

Coneus, Katja, Johannes Gernandt and Marianne Saam (2009), Noncognitive Skills, School Achievements and Educational Dropout, ZEW Discussion Paper 09-019, Mannheim.

Cornelissen, T., and C. Pfeifer (2007), The Impact of Participation in Sports on Educational Attainment: New Evidence from Germany, IZA Discussion Paper 3160, Bonn.

Destatis (2008), 2,4 Millionen nichteheliche Lebensgemeinschaften in Deutschland, Press-release No. 307, Statistisches Bundesamt, Wiesbaden.

Deutscher Bundestag (2009), Bericht über die Lebenssituation junger Menschen und die Leistungen der Kinder- und Jugendhilfe in Deutschland - 13. Kinder- und Jugendbericht, Drucksache 16/12860.

Fernandes, A., and T. Gabe (2009), Disconnected Youth: A Look at 16- to 24-Year Olds Who Are Not Working or In School, Report for Congress, Congressional Research Service.

Franz, Wolfgang (1982), Youth Unemployment in the Federal Republic of Germany: Theory, Empirical Results and Policy Implications. Tübingen: Mohr Siebeck. 
Franz, W., J. Inkmann, W. Pohlmeier, and V. Zimmermann (2000), Young and Out in Germany: On the Youth's Chances of Labor Market Entrance in Germany, in: D.G. Blanchflower and R.B. Freeman (Eds.), Youth Employment and Joblessness in Advanced Countries, Chicago University Press, 381- 425.

Gomez-Salvador, R., and N. Leiner-Killinger (2008), An analysis of youth unemployment in the euro area, Occasional Paper Series No. 89, European Central Bank.

Heckman, J.J. (2007), The Economics, Technology and Neuroscience of Human Capability Formation. Proceedings of the National Academy of Sciences, 104 (3), 132250-132255.

Heckman, J. J., and Y. Rubinstein (2001), The Importance of Noncognitive Skills: Lessons from the GED Testing Program, American Economic Review, 91 (2), $145-149$.

Laucht, Manfred, Jens Treutlein, Dorothea Blomeyer, et al. (2009), Interaction between the 5-HTTLPR serotonin transporter polymorphism and environmental adversity for mood and anxiety psychopathology: Evidence from a high-risk community sample of young adults, The International Journal of Neuropsychopharmacology, 12, 737-747.

Lechner, M. (2008), Long-Run Labour Market Effects of Individual Sports Activities, IZA Discussion Paper No. 3559, Bonn.

MaCurdy, T., B. Keating, and S. S. Nagavarapu (2006), Profiling the Plight of Disconnected Youth in America, William and Flora Hewlett Foundation, Palo Alto, CA: Stanford University.

Martinez, T., and M. Wald (2003), Connected by 25: Improving the Life Chances of the Country's Most Vulnerable 14-24 Year Olds, William and Flora Hewlett Foundation, Palo Alto, CA: Stanford University.

Montada, L., and R. Oerter (2002), Entwicklungspsychologie. 5. vollständig überarbeitete Auflage, Beltz-Verlag, Weinheim.

Rasmussen, A.W. (2009), Family Structure Changes and Children's Health, Behavior, and Educational Outcomes, Manuscript, Aarhus University.

Rotter, J. B. (1966), Generalized Expectancies for Internal versus External Control of Reinforcement, Psychological Monographs, 80 (1), Whole No. 609.

Verick, S. (2009), Who Is Hit Hardest during a Financial Crisis? The Vulnerability of Young Men and Women to Unemployment in an Economic Downturn, IZA Discussion Paper No. 4359, Bonn.

Wagner, G. G., J. R. Frick, and J. Schupp (2007), The German Socio-Economic Panel Study (SOEP) - Scope, Evaluation and Enhancements, Schmollers Jahrbuch - Journal of Applied Social Science Studies 127 (1), 139 - 169. 


\section{Appendix}

Table A1: Transition matrix for the 17-, 18- and 19-year-olds

\begin{tabular}{ccccc}
\hline \hline DC in $\mathbf{~}$ & $\mathbf{0}$ & $\mathbf{D C}$ in $\mathbf{t + 3}$ & & \\
\hline $\mathbf{0}$ & 1,647 & 169 & 2,103 & 3,919 \\
$\mathbf{\%}$ & $42,03 \%$ & $4,31 \%$ & $53,66 \%$ & $100,00 \%$ \\
$\mathbf{1}$ & 71 & 14 & 121 & 206 \\
$\mathbf{\%}$ & $34.47 \%$ & $6.80 \%$ & $58.74 \%$ & $100.00 \%$ \\
\hline Total & $\mathbf{2 2 2 4}$ & $\mathbf{1 8 3}$ & $\mathbf{1 7 1 8}$ & $\mathbf{4 1 2 5}$ \\
\hline \hline
\end{tabular}

Source: Sample B from SOEP, 1991-2007; own calculations.

Table A2: Transition matrix for the 18- and 19-year-olds

\begin{tabular}{ccccc}
\hline \hline DC in $\mathbf{~}$ & $\mathbf{0}$ & $\mathbf{D C}$ in $\mathbf{~ + 2}$ & & \\
\hline $\mathbf{0}$ & 2792 & 278 & 932 & 4002 \\
$\%$ & $69.77 \%$ & $6.95 \%$ & $23.29 \%$ & $100.00 \%$ \\
$\mathbf{1}$ & 124 & 39 & 72 & 235 \\
$\%$ & $52.77 \%$ & $16.60 \%$ & $30.64 \%$ & $100.00 \%$ \\
\hline Total & $\mathbf{2 9 1 6}$ & $\mathbf{3 1 7}$ & $\mathbf{1 0 0 4}$ & $\mathbf{4 2 3 7}$ \\
\hline \hline
\end{tabular}

Source: Sample B from SOEP, 1991-2007; own calculations. 